\title{
Análise de viabilidade econômica de um confinamento de bovinos de corte
}

\author{
Economic viability analysis of feedlot beef cattle
}

\section{Analyse de viabilité économique des parcs d'engraissement de bovins de boucherie}

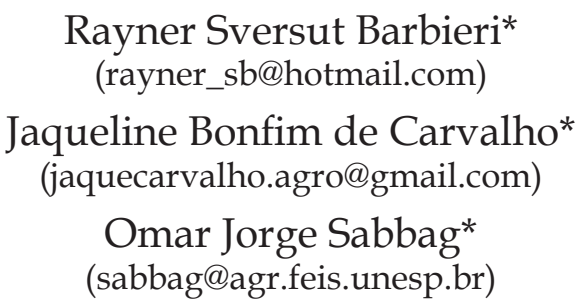

Análisis de viabilidad económica de un corral de engorde de ganado de carne

Recebido em 11/12/2015; revisado e aprovado em 28/01/2016; aceito em 30/03/2016

DOI: http:/ / dx.doi.org/10.20435/1984-042X-2016-v.17-n.3(01)

\begin{abstract}
Resumo: A adoção do sistema de confinamento de bovinos permite maior controle dos custos, porém o levantamento dos gastos deve ser bem planejado. O presente estudo objetivou analisar e avaliar a viabilidade econômica da produção de um confinamento de bovinos de corte, em Auriflama, SP. Os custos com insumos integraram 85,14\%, porém obteve índice de lucratividade $68,55 \%$ e valor presente líquido positivo a partir do $4^{\circ}$ ano. Considerando as análises estudadas, a pecuária apresenta ser uma atividade rentável e viável.
\end{abstract}

Palavras-chave: pecuária; custos; rentabilidade; gestão.

Abstract: The adoption of the cattle feedlot system allows greater control of costs, however, the survey of spending must be well planned. This study aimed to analyze and evaluate the economic feasibility of producing a feedlot beef cattle in Auriflama/SP. Input costs have integrated 85.14\%, however obtained profitability index $68.55 \%$ and positive net present value from the 4 th year. Considering the analysis studied the livestock had to be a profitable and viable activity.

Key words: livestock; costs; profitability; management.

Résumé: L'adoption du système de bovins d'engraissement permet une plus grande maîtrise des coûts, cependant, l'enquête sur les dépenses doit être bien planifiée. Cette étude visait à analyser et évaluer la faisabilité économique de la production un parc d'engraissement de bovins de boucherie dans Auriflama/SP. Les coûts des intrants ont intégré 85.14\%, cependant obtenu indice de rentabilité $68,55 \%$ et la valeur actualisée nette positive à partir de la 4ème année. Considérant l'analyse a étudié bétail devait être une activité rentable et viable.

Mots-clés: bétail; coûts; rentabilité; gestion.

Resúmen: La adopción del sistema de engorde de ganado permite un mayor control de los costos, sin embargo, la encuesta de gasto debe ser bien planeado. Este estudio tuvo como objetivo analizar y evaluar la viabilidad económica de la producción de una carne de ganado de engorda en Auriflama/SP. Costos de los insumos han integrado 85,14\%, sin embargo obtenido índice de rentabilidad $68,55 \%$ y el valor presente neto positivo desde el cuarto año. Teniendo en cuenta el análisis estudió la ganado tenía que ser una actividad rentable y viable.

Palabras clave: ganado; costos; rentabilidade; gestión.

\section{INTRODUÇÃO}

O agronegócio brasileiro ocupa posição de destaque no cenário econômico nacional, devido a sua importante participação na economia brasileira
(ANDRADE et al., 2013), sendo responsável por aproximadamente $23 \%$ do Produto Interno Bruto (PIB) em 2014 (CENTRO DE ESTUDOS AVANÇADOS EM ECONOMIA APLICADA [CEPEA], 2014).

\footnotetext{
* Universidade Estadual Paulista Júlio de Mesquita Filho (UNESP), Ilha Solteira, São Paulo, Brasil.
} 
No balanço de 2014, o desempenho positivo desse setor é explicado pelo ramo pecuário. Com crescimentos mensais sucessivos, a renda da pecuária acumulou expansão de 6,91\% em relação a 2013 (BARROS et al., 2014). A atividade pecuária é um dos setores mais importantes do agronegócio brasileiro. Ela tem participação significativa no PIB e gera milhares de empregos diretos e indiretos (CEPEA, 2014).

O número de cabeças bovinas no Brasil evoluiu nos últimos anos, segundo dados do Instituto Brasileiro de Geografia e Estatística (IBGE, 2014); de 1990 para 2013, o número de cabeças foi de 147 milhões para 211 milhões. Já no estado de São Paulo, o número de cabeças diminuiu de 12 milhões para 10 milhões de cabeças, muito em função da perda de competitividade da pecuária para outras culturas agrícolas no estado, principalmente a cana-de-açúcar.

Fica evidente que a competitividade com outras opções de uso do solo, como a agricultura, por exemplo, tem forçado o setor pecuário a buscar maior eficiência produtiva e econômica dentro do segmento agropecuário. Dessa forma, como estratégia para manter o constante fornecimento de carne para os mercados interno e externo, o bovino brasileiro é normalmente alimentado em confinamentos, principalmente na época da seca do ano, em que a disponibilidade e qualidade das pastagens são reduzidas. Segundo Moreira et al. (2010), confinamentos que se desenvolvem dentro de uma propriedade com expressiva atividade agrícola servem como uma opção de diversificação de investimentos.

Quando se trata de investimento, este se refere aos gastos e, ao enfatizar os custos de produção, devem-se definir os conceitos em termos econômicos. O custo econômico considera os custos explícitos, referentes ao desembolso efetivamente realizado, e os custos implícitos, relativos àqueles para os quais não ocorrem desembolsos efetivos, como é o caso da depreciação e do custo de oportunidade, que se refere ao valor que um determinado fator poderia receber em algum uso alternativo (CASTRO et al., 2009).

O custo operacional é outro conceito importante a ser retratado, que refere ao custo de todos os recursos que exigem desembolso monetário por parte da atividade produtiva para sua recomposição, incluindo a depreciação; e o seu alvo na análise é a opção de decisão em casos em que os retornos financeiros sejam inferiores aos de outras alternativas, representadas pelo custo de oportunidade (REIS, 2007).

A adoção do sistema de confinamento de bovinos permite maior controle dos custos de produção dentro e fora da porteira; por consequência, aumenta ganhos do produtor. Entretanto o levantamento dos gastos com o confinamento deve ser bem planejado devido ao elevado volume de recurso financeiro necessário. A maior parte do custo operacional total está relacionada à compra dos animais e depois à dieta as quais totalizam em quase $90 \%$ (BARBOSA et al., 2006).

A avaliação da atividade produtiva pode ser realizada tomando por base os custos de produção e os preços de venda do produto. Essa relação possibilita a análise financeira, levando em conta a remuneração obtida com a comercialização, a cobertura do custeio, dos custos variável, operacional e total. O resultado pode gerar, ainda, os índices de análise quantitativa do ponto de equilíbrio e a geração de diversos indicadores que podem auxiliar na análise de rentabilidade da unidade produtiva (CONAB, 2010).

Além desse problema relacionado ao custo, o confinamento necessita de investimentos na construção de toda a estrutura necessária para seu funcionamento. Com isso, é preciso fazer uma avaliação detalhada de todo o investimento necessário e verificar a viabilidade econômica do projeto, pois assim se pode ver a atra- 
tividade do sistema produção de gado de corte (CUNHA et al., 2014).

Para demonstrar a viabilidade econômica de uma atividade, conforme preconizam Souza e Clemente (2004), torna-se necessário efetuar uma avaliação de investimentos, sendo determinada por um fluxo de caixa descontado. Dessa forma, a decisão de fazer investimento de capital é parte de um processo que envolve a avaliação das alternativas que atendam as especificações técnicas dos investimentos. Os indicadores gerados auxiliarão o processo decisório, dados os riscos envolvidos.

$\mathrm{Na}$ avaliação de investimentos através de fluxos de caixa descontados a valor presente, torna-se necessário dimensionar o grau de risco, por meio de uma taxa de desconto que corresponda ao custo de capital ou taxa mínima de atratividade
(TMA), aliado ao horizonte de análise do investimento. Assim, utilizam-se técnicas de avaliação, tais como o Valor Presente Líquido (VPL) e a Taxa Interna de Retorno (TIR) (DAMODARAN, 1997).

Nesse contexto, objetivou-se, com esse trabalho, avaliar economicamente um sistema de confinamento para uma propriedade de bovinos de corte, identificando os itens relevantes para os custos de produção, bem como os parâmetros relacionados à viabilidade da atividade.

\section{MATERIAL E MÉTODOS}

O estudo foi realizado em uma propriedade localizada no município de Auriflama, SP (Figura 1), situada aproximadamente à latitude sul $-20^{\circ} 41^{\prime} \mathrm{e}$ longitude oeste $50^{\circ} 33^{\prime}$, no período entre maio/2014 e dezembro/2014.

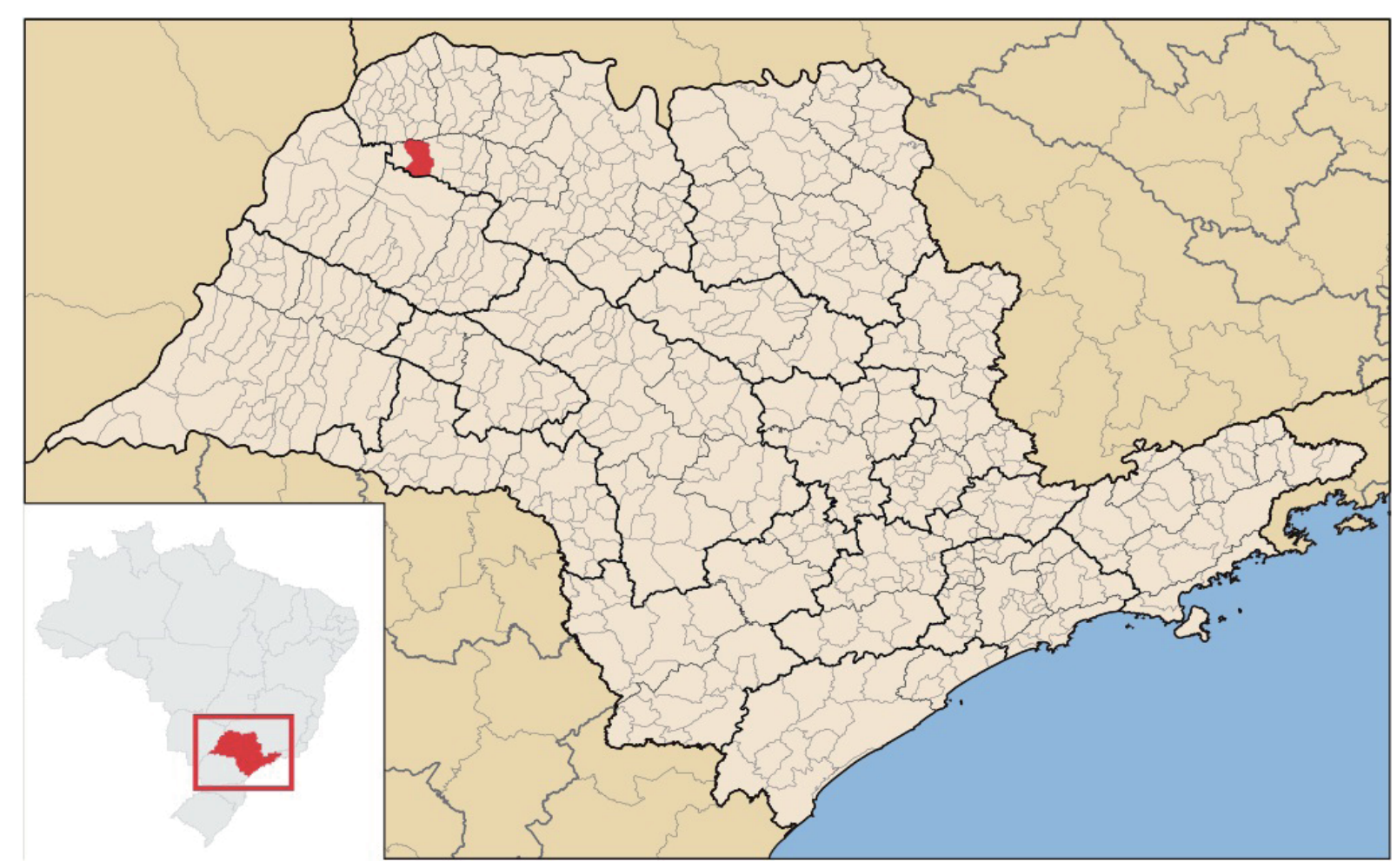

Figura 1 - Município de Auriflama no estado de São Paulo Fonte: Adaptado de IBGE cidades. 
Neste trabalho, utilizou-se a metodologia de estudo de caso. O "estudo de caso" representa uma investigação empírica e compreende um método abrangente, com a lógica do planejamento, da coleta e da análise de dados, podendo incluir tanto estudos de caso único quanto de múltiplos, assim como abordagens quantitativas e qualitativas de pesquisa (YIN, 2001). Nesse sentido, essa modalidade de pesquisa é entendida como uma metodologia ou como a escolha de um objeto de estudo definido pelo interesse em casos individuais. Visa à investigação de um caso específico, bem delimitado, contextualizado em tempo e lugar para que se possa realizar uma busca circunstanciada de informações.

A propriedade estudada foi escolhida em razão de sua tecnologia adotada, bem como a presença de controle zootécnico e gerencial, de modo a aproximar da realidade encontrada na região, permitindo que os resultados encontrados tivessem parâmetros comparativos.

A propriedade possui uma sede, três casas para funcionários, um galpão de armazenamento de grãos, insumos e implementos, uma estrutura de confinamento com capacidade estática de 600 animais e um curral de manejo (apartação, seringa, brete, tronco de contenção, balança e embarcadouro) com capacidade de 200 animais. Toda a área correspondente a instalações e benfeitorias corresponde a cinco hectares.

Foram confinados 330 animais, com peso médio inicial de $380,33 \mathrm{Kg}$, sem raça definida (SRD), ou seja, animais mestiços oriundos de cruzamentos entre raças de aptidão leiteira e de corte. Os animais foram devidamente vermifugados e divididos por peso e idade antes de entrarem no confinamento para receber as dietas de terminação.

Foram utilizados 4,86 hectares de cana-de-açúcar (Saccharum L.) e 4 hectares de milho (Zea mays), para servir como fonte de volumoso para os animais. A cana-de-açúcar foi adicionada à ração in natura, e o milho foi ensilado.

As dietas foram calculadas com base nas exigências nutricionais descritas por Valadares Filho et al. (2000), com equações de acordo com o National Research Council (2000) e, por fim, otimizadas com a ferramenta de análise de dados Solver, constituindo-se de duas dietas de adaptação ao confinamento nos primeiros 15 dias e uma dieta final. O consumo de ração foi ad libtum ${ }^{1}$, com uma distribuição de três a quatro vezes por dia, dependendo do consumo dos animais para evitar sobra de cocho, realizadas com auxílio de um Vagão Kuhn Misturador/Distribuidor com balança.

Os custos foram classificados de acordo com a metodologia do Instituto de Economia Agrícola de São Paulo (IEASP), descrita por Matsunaga et al. (1976), na qual o custo operacional total (COT) é representado pela composição das operações mecanizadas e manuais, insumos, depreciações e encargos financeiros (juros de custeio). Dessa forma, o levantamento de custos constitui-se em um método de avaliação de desempenho econômico e técnico da atividade produtiva (SIMÕES et al., 2007).

Para o custo operacional efetivo (COE), foram contabilizados os gastos com materiais consumidos, bem como o tempo relacionado ao uso de máquinas / implementos e à mão de obra incorporada para cada operação, definindo-se, assim, os respectivos coeficientes técnicos (hora máquina ${ }^{-1}$ e homem dia ${ }^{-1}$ ). Os preços médios na região foram coletados em unidade de moeda Real ( $R \$)$, referentes ao ano de 2014.

Dessa forma, os respectivos cálculos do COT foram correspondentes aos itens:

1) Operações mecanizadas - Sendo composto por: a) Despesas com combustível: quantidade de combustível consumido (em litros) pelo trator, multiplicado

\footnotetext{
1 Fornecimento alimentar "à vontade".
} 
pelo valor do litro de óleo diesel; b) lubrificantes: $20 \%$ do valor das despesas com combustível; c) reparos e manutenção: $8 \%$ a.a. do valor inicial da máquina, dividido pelo número de horas que a máquina trabalha em um ano; d) tratorista: custo da hora (em R\$); e) abrigo: $1 \%$ a.a. do valor inicial da máquina, dividido pelo número de horas trabalhadas no ano; e f) seguro: 0,75\% a.a. do valor inicial da máquina, dividido pelo número de horas trabalhadas no ano. A soma de todos esses gastos resultou no custo horário das operações mecanizadas;

2) Operações manuais - relacionou-se, para cada etapa do ciclo produtivo, o fator multiplicativo correspondente ao número de horas de trabalho pelo coeficiente técnico homens dia $^{-1}$ (HD) pelo valor médio da região ( $\left.\mathrm{R} \$ 30,00 \mathrm{dia}^{-1}\right)$;

3) Materiais (ou insumos) - referiu-se às principais despesas correspondentes com vacinas, medicamentos, dentre outros, sendo obtido pela multiplicação de cada quantidade utilizada pelo seu respectivo preço;

4) Juros de custeio -relacionaram-se os encargos financeiros calculados sob a metade do COE, aplicados à taxa de 5,5\% a.a. (PRONAF), proporcional ao ciclo produtivo;

5) Depreciação - Foi calculada pelo método linear (ou depreciação constante), em relação ao conjunto de bens correspondentes à infraestrutura da atividade, associados ao valor de aquisição e correspondente valor residual ao final da vida útil de cada bem;

6) Encargos sociais - referiu-se ao valor total correspondente à mão de obra manual, acrescida de 33\%, correspondente aos direitos trabalhistas, tais como férias, $13^{\circ}$, INSS, dentre outros;

7) Despesas gerais - correspondentes ao valor de $5 \%$ atribuído ao total do $\mathrm{COE}$, referente a gastos diversos, como telefone, administração e conservação de cercas.

Empregaram-se no trabalho os indicadores de análise de rentabilidade proposto por Martin et al. (1998), os quais são definidos como:

a) Receita Bruta (RB): constituída pela receita esperada para determinada produção por hectare para cada época de corte, para um preço de venda pré-definido, ou efetivamente recebido, ou seja, $\mathrm{RB}=\operatorname{Pr} \times \mathrm{Pu}$, em que: $\mathrm{Pr}=$ produção da atividade por unidade de área e $\mathrm{Pu}=$ preço unitário do produto;

b) Lucro Operacional (LO): resultante da subtração da receita bruta e custos totais, medindo a lucratividade da atividade no curto prazo, sendo expresso por $\mathrm{LO}=\mathrm{RB}-\mathrm{COT}$;

c) Índice de Lucratividade (IL): resultante da relação entre o lucro operacional e a receita bruta, em percentagem, mostrando a taxa disponível de receita da atividade após o pagamento de todos os custos operacionais, expresso por IL = (LO / RB) x 100;

d) Ponto de Nivelamento (PN): indicador de produção ou custo de equilíbrio, para que a atividade não incorra em prejuízos, dado por $\mathrm{PE}=\mathrm{COT} / \mathrm{Pu}$ (produção de equilíbrio) e PC = COT / produção (preço de custo).

Sequencialmente, foi montado um fluxo de caixa para a análise da viabilidade econômica do investimento (NORONHA, 1981), o qual refletiu os valores das entradas e saídas dos recursos e produtos. Então se determinou:

Payback Period: visando calcular o tempo que o pecuarista levará para recuperar o investimento realizado em determinado projeto;

Relação Benefício-Custo: expressa pela divisão entre os valores positivos e negativos a valor presente de um fluxo de caixa, ressaltando que, para aprovação do projeto, é necessário haver um índice maior que um, o que implicará um valor positivo do VP do projeto;

Valor Presente Líquido (VPL): refere-se ao retorno mínimo que deve ser obtido por um projeto, de forma a manter inalterado o valor de mercado da empre- 
sa, considerando um custo de capital de $6 \%$ a.a., sendo expresso por:

$$
\mathrm{VPL}=\sum_{\mathrm{t}=0}^{\mathrm{n}} \mathrm{VF} /(1+\mathrm{i})^{\mathrm{t}}
$$

em que VPL = valor presente líquido; VF = valor do fluxo líquido (diferença entre entradas e saídas); $\mathrm{n}$ = número de fluxos; $\mathrm{i}$ $=$ taxa de desconto; $\mathrm{t}=$ período de análise (i $=1,2,3 \ldots)$.

d) Taxa Interna de Retorno (TIR): é a taxa de juros que torna o valor presente das entradas de caixa igual ao valor presente das saídas de caixa do investimento, expresso por:

$$
\sum_{\substack{\mathrm{t}=0 \\ \mathrm{~L}_{\mathrm{t}}(1+i)^{\mathrm{t}}=0}}^{\mathrm{n}}
$$

em que i éa Taxa Interna de Retorno (TIR), $\mathrm{L}_{\mathrm{t}}$ são os fluxos líquidos de caixa e $\mathrm{t}$ são os períodos de produção da cultura, que variam de zero até $n$.

\section{RESULTADOS E DISCUSSÃO}

A estrutura do capital fixo para implantação e produção de bovinos de corte no sistema de confinamento em Auriflama totalizou-se em R\$1.708.755,22 (Tabela 1), no qual está contido o capital fundiário, capital de exploração fixo e capital de exploração circulante, com destaque para as benfeitorias necessárias para o bom funcionamento do sistema de confinamento, as quais constituem $47,62 \%$ da estrutura da atividade.
As máquinas e equipamentos relacionados foram utilizados durante o ciclo produtivo da atividade para o preparo do solo, plantio e colheita de milho e cana-de-açúcar, ensilagem de milho, mistura e distribuição diária da ração e manutenção geral do confinamento. Elas perfizeram $22,07 \%$ da estrutura e investimentos fixos da atividade.

A estimativa de custo operacional efetivo e total de produção de bovinos de corte no sistema de confinamento encontra-se na Tabela 2. O custo operacional efetivo (COE) foi de $\mathrm{R} \$ 187.742,09$.

Convém ressaltar que os custos com operações manuais e mecanizadas são referentes a oito meses de trabalho, desde o preparo do solo para produção de milho e cana-de-açúcar, como fonte de volumoso, até os tratos diários dos animais, que constituíram 14,86\% do COE. Já os custos com insumos (vacinas, vermífugo e ração) foram de $\mathrm{R} \$ 159.848,78$ e integraram $85,14 \%$ do COE.

Barbosa et al. (2006) encontraram percentual de $61 \%$ do COT, comprovando que os gastos com insumos e alimentos no sistema de confinamento são altos e constituem a maior parte do custo operacional da atividade. Esses ingredientes todos possuem preços altos no mercado e sofrem influência de vários fatores ligados não somente ao setor agrícola (MEDEIROS; CUNHA; WANDER, 2015).

O custo total de produção nesse ciclo de confinamento foi de R $\$ 252.160,10$, considerando a adição ao COE da depreciação de máquinas, encargos sociais, despesas gerais e encargos financeiros. 
Tabela 1 - Estrutura do capital existente e investimentos fixos para a implantação e produção de bovinos de corte (Auriflama, SP, 2014)

\begin{tabular}{|c|c|c|c|c|}
\hline \multirow[t]{2}{*}{ Item } & $\begin{array}{c}\text { Quanti- } \\
\text { dade }\end{array}$ & Valor Unitário & Valor total & \multirow[t]{2}{*}{$\%$} \\
\hline & un. & \multicolumn{2}{|c|}{$\mathrm{R} \$$} & \\
\hline \multicolumn{5}{|l|}{ I- Capital fundiário } \\
\hline Cana-de-açúcar (hectares) & 4,86 & $2.194,53$ & $10.665,42$ & 0,62 \\
\hline Milho (hectares) & 4 & $2.272,50$ & $9.090,00$ & 0,53 \\
\hline \multicolumn{5}{|l|}{ Benfeitorias ${ }^{* * *}$} \\
\hline Estrutura de confinamento & 1 & $34.000,00$ & $34.000,00$ & 1,99 \\
\hline Galpão m² & 300 & 666,67 & $200.000,00$ & 11,70 \\
\hline Casa de funcionário $\left(50 \mathrm{~m}^{2}\right)$ & 3 & $60.000,00$ & $180.000,00$ & 10,53 \\
\hline Sede $\mathrm{m}^{2}$ & 220 & 909,09 & $199.999,80$ & 11,70 \\
\hline Curral de manejo & 1 & $200.000,00$ & $200.000,00$ & 11,70 \\
\hline \multicolumn{5}{|l|}{ II- Capital de exploração fixo** } \\
\hline Animais de trabalho (cavalos) & 2 & $1.500,00$ & $3.000,00$ & 0,18 \\
\hline \multicolumn{5}{|l|}{ Máquinas e equipamentos: } \\
\hline Trator* (John Deere 6300 100cv) & 1 & $50.000,00$ & $50.000,00$ & 2,93 \\
\hline Trator* (John Deere 5603 85cv com PCA) & 1 & $60.000,00$ & $60.000,00$ & 3,51 \\
\hline Trator* (John Deere 5703 85cv com redutor) & 1 & $60.000,00$ & $60.000,00$ & 3,51 \\
\hline Vagão Kuhn Misturador/Distribuidor & 1 & $70.000,00$ & $70.000,00$ & 4,10 \\
\hline Forrageira JF-92 & 3 & $7.000,00$ & $21.000,00$ & 1,23 \\
\hline Vagão Penha Distribuidor $8 \mathrm{~m} 3$ & 2 & $9.000,00$ & $18.000,00$ & 1,05 \\
\hline Distribuidor de Calcário Tatu 3 toneladas & 1 & $12.000,00$ & $12.000,00$ & 0,70 \\
\hline Grade 28/16 Tatu & 1 & $15.000,00$ & $15.000,00$ & 0,88 \\
\hline Niveladora & 1 & $7.000,00$ & $7.000,00$ & 0,41 \\
\hline Semeadeira Vicon & 1 & $7.000,00$ & $7.000,00$ & 0,41 \\
\hline Trituradera de grãos Nogueira & 1 & $5.000,00$ & $5.000,00$ & 0,29 \\
\hline Plantadeira de 2 linhas Tatu & 1 & $6.000,00$ & $6.000,00$ & 0,35 \\
\hline Pulverizador 600L Jactu & 1 & $6.000,00$ & $6.000,00$ & 0,35 \\
\hline Carreta basculante de trator & 1 & $10.000,00$ & $10.000,00$ & 0,59 \\
\hline Surcador/Adubadeira Tatu & 1 & $15.000,00$ & $15.000,00$ & 0,88 \\
\hline Rocadeira hidráulica & 1 & $7.000,00$ & $7.000,00$ & 0,41 \\
\hline Tombador Iveca & 1 & $8.000,00$ & $8.000,00$ & 0,47 \\
\hline \multicolumn{5}{|l|}{ III- Capital de exploração circulante } \\
\hline \multicolumn{5}{|l|}{ Animais para a venda: } \\
\hline Novilhos (até 36 meses) & 330 & $1.500,00$ & $495.000,00$ & 28,97 \\
\hline Total & & & $1.708 .755,22$ & 100 \\
\hline
\end{tabular}


Tabela 2 - Estimativa anual do custo operacional da produção de bovinos de corte (Auriflama, SP, 2014).

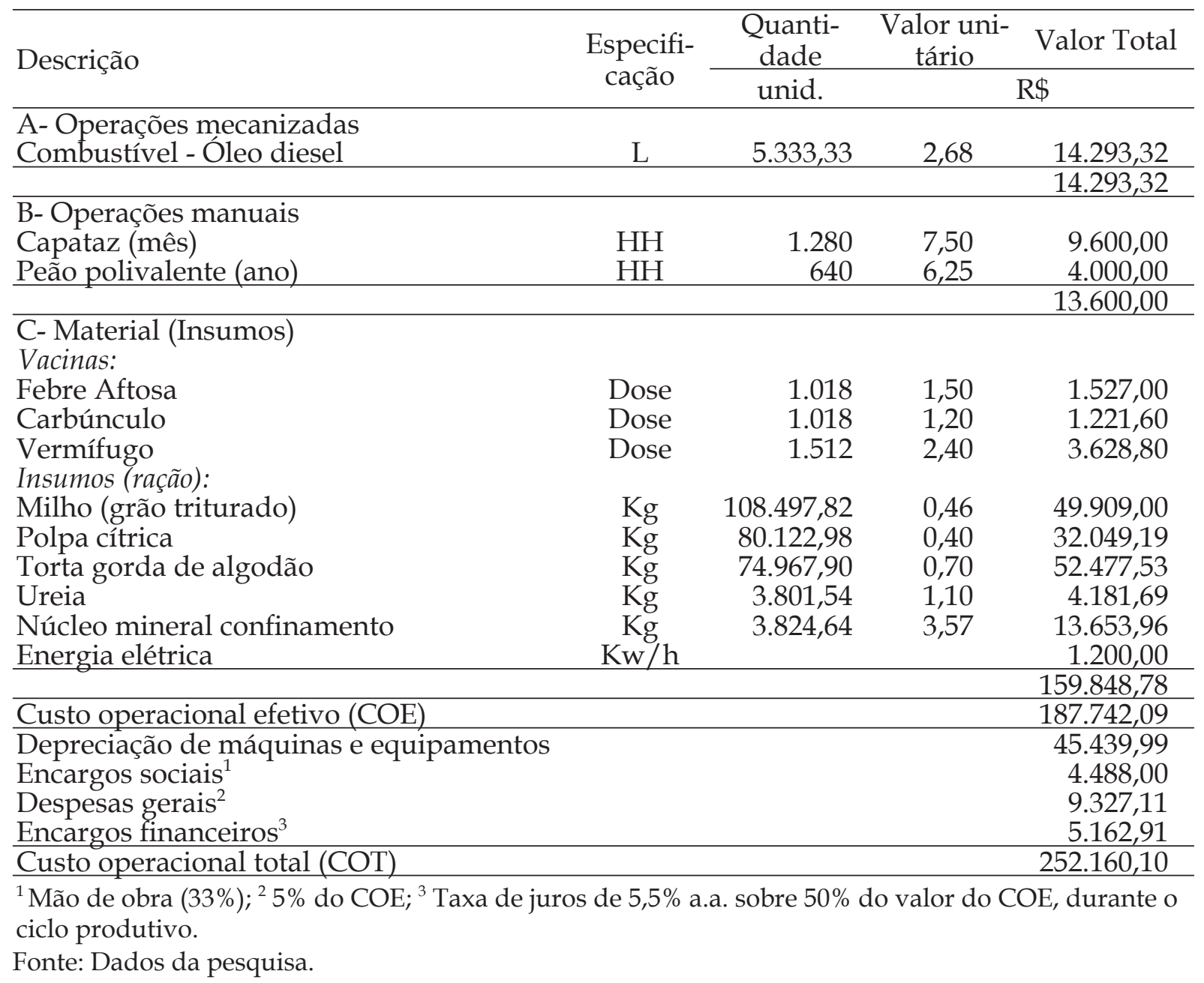

Em 2014, foi registrado o maior valor da série histórica de preços do Cepea (R\$132,24), de julho de 1997 a setembro de 2014. A oferta restrita de animais para reposição e abate decorrente, dentre outros fatores, da seca prolongada iniciada no final de 2013, contribuiu marcadamente para o aumento dos preços pagos aos pecuaristas (CEPEA, 2014). Após setembro, o preço da arroba ainda aumentou e atingiu novos patamares, portanto tratou-se de um ótimo ano para os pecuaristas, sendo que os animais foram adquiridos com preços inferiores ( $\mathrm{R} \$ 118,32$ arroba $\left.^{-1}\right)$, que ainda eram considerados onerosos pelo produtor na época, e vendidos em uma alta de preço histórica.

Essa alta de preços atingiu também os animais de reposição. A cotação do bezerro macho começou, em 2015, ao redor de $R \$ 1.200,00$ reais por cabeça e chegou a bater $\mathrm{R} \$ 1.500,00$ reais por cabeça. Aconteceram leilões que relataram cotações de bezerro ao redor de $\mathrm{R} \$ 2.000,00$ reais por cabeça. Tudo isso aconteceu no primeiro semestre, época em que o bezerro subiu no Brasil inteiro e deixou os compradores preocupados, e os vendedores eufóricos. Dessa maneira, o produtor deve ficar atento às tendências do ciclo pecuário para manter-se ativo e crescente na atividade; em seu planejamento para o ano seguinte, a preocupação deve ser o preço da reposição, só assim ele saberá se o seu ciclo de produção trouxe bons resultados.

A rentabilidade anual do custo operacional de produção de bovinos de corte 
em sistema de confinamento no ciclo atual é representada na Tabela 3. A receita bruta, que representa diretamente o número de animais vendidos (6.168,14 arrobas) para o frigorífico, a um preço médio de $\mathrm{R} \$ 130,00$ arroba $^{-1}$, foi de $\mathrm{R} \$ 801.858,20$.

O lucro operacional, representado pela diferença entre a receita bruta e COT, foi de $\mathrm{R} \$ 549.698,10$. Isso representa um índice de lucratividade no ciclo de $68,55 \%$, ou seja, para o produtor pagar os seus custos totais seria necessário uma produção de equilíbrio de 1.940 arrobas, porém houve uma produção superior em $218 \%$. Sendo assim, a produção de bovinos de corte apresentou-se lucrativa e rentável.

Tabela 3 - Rentabilidade anual do custo operacional de produção de bovinos de corte (Auriflama, SP, 2014)

\begin{tabular}{lr}
\hline Discriminação & Resultados \\
\hline Receita Bruta (R\$) & $801.858,20$ \\
Custo Total de produção (R\$) & $252.160,10$ \\
Lucro operacional (R\$) & $549.698,10$ \\
Índice de lucratividade (\%) & 68,55 \\
Produção de equilíbrio (@) & 1.940 \\
Preço de custo @-1 (R\$) & 40,88 \\
\hline
\end{tabular}

Fonte: Dados de pesquisa.

A rentabilidade desse sistema foi superior comparativamente a outros trabalhos apresentados na literatura. Lopes et al. (2013) apresentaram rentabilidade máxima de $10,36 \%$ analisando dois sistemas de confinamento. Lopes e Magalhães (2005) também realizaram um estudo de caso com a terminação de bovinos de corte em condições de confinamento e obtiveram uma rentabilidade de apenas 1,3\%.

Damasceno, Lopes e Costa (2012) realizaram um estudo de caso em uma produção de bovinos de corte em condição de pastejo extensivo e obtiveram rentabilidade negativa em 5,25\%. Já Silveira, Soares e Silva (2013) mostram dados promissores para a fase de recria de bovinos de corte, alcançando a rentabilidade de $72,28 \%$ em pastagem rotacionada e $55,80 \%$ em pastagem extensiva.

Para a análise de investimento (Tabela 4), o VPL já se torna favorável para o $4^{\circ}$ ano, resultante da adição de todos os fluxos de caixa para a data inicial, superando-se assim, o investimento inicial da atividade. De acordo com Samanez (2009), o objetivo do VPL é encontrar alternativas de investimento que valham mais do que custam, alternativas estas que tenham um valor presente líquido positivo, indicando assim a viabilidade econômica da alternativa. Nessa condição, o investimento deve ser aceito, inferindo que o custo de capital já foi introduzido na análise e que a TIR de 10,91\% a.a. superou em aproximadamente $82 \%$ da taxa mínima de atratividade (TMA) correspondente à atividade. Segundo Bruni e Famá (2007), quando a TIR mostrar-se superior à TMA, o projeto deverá ser aceito, pressupondo que as expectativas de ganhos sejam maiores em relação ao custo de capital considerado no trabalho.

Por outro lado, Santos e Jurca (2013), em trabalho realizado no centro-oeste brasileiro, com gado terminado com peso médio de 19 arrobas, semelhante ao presente estudo, porém com um preço da arroba bem inferior ( $\$ \$ 99,91)$, apresentaram resultado insatisfatório, no qual a taxa interna de retorno (TIR) foi inferior à taxa mínima de atratividade $(7,65 \%<8 \%$ a.a.); valor presente líquido (VPL) negativo e um payback descontado de 10,21 anos, superior ao horizonte de 10 anos proposto para recuperar o investimento. 
Pacheco et al. (2012) utilizaram dados de desempenho de 18 animais 5/8 Nelore 3/8 Charolês contemporâneos, provenientes do mesmo rebanho, castrados e com idade e peso médios de 713 dias e $361 \mathrm{~kg}$, com dieta semelhante ao presente estudo, formulada pelo NRC. Nesse estudo, houve possibilidade de o investimento em qualquer peso de abate gerar o valor presente líquido positivo. A TIR foi maior que a TMA em todos os casos, porém foi superior $(0,4868 \%)$ para os pesos de abate de 425 e $467 \mathrm{~kg}$.
Observa-se ainda que os principais indicadores de fluxo de caixa possuem um crescimento expressivo, à medida que amplia o horizonte de planejamento. Assim, destaca-se que a referida taxa mostrou-se superior, comparativamente a outros trabalhos do segmento agropecuário analisados com um horizonte de mesmo período, como a pecuária extensiva, podendo aumentar o nível de aceitação da atividade, por meio da diversificação com o plantio de eucalipto (HUDSON; GARCIA, 2009).

Tabela 4 - Fluxo de caixa, valor presente líquido, TIR, relação B/C e Pay Back Period, para a produção de bovinos de corte (Auriflama, SP, 2014)

\begin{tabular}{lrrrr}
\hline Discriminação & $\mathbf{0}$ & \multicolumn{1}{c}{$\mathbf{1}$} & \multicolumn{1}{c}{$\mathbf{4}$} & \multicolumn{1}{c}{$\mathbf{1 0}$} \\
\hline Investimentos & $-1.708 .755,22$ & & & \\
Custo Operacional Total & & $252.160,10$ & $252.160,10$ & $252.160,10$ \\
Receita bruta & & $801.858,20$ & $801.858,20$ & $801.858,20$ \\
Fluxo líquido anual & & $549.698,10$ & $549.698,10$ & $549.698,10$ \\
Fluxo líquido acumulado & & $-1.159 .057,12$ & $490.037,18$ & $3.788 .225,78$ \\
VPL (R\$) & & $-1.190 .172,11$ & $196.006,75$ & $2.337 .070,65$ \\
TIR (\%) & - & 10,91 & 29,80 \\
Pay Back Period (anos) & 4 & & & \\
B/C & & 0,32 & 1,29 & 3,22 \\
\hline
\end{tabular}

Fonte: Dados de pesquisa.

Com relação ao indicador benefício/ custo (IBC), verifica-se que há um retorno de $29 \%$ para o pecuarista para o período inicial de análise positiva, considerando este parâmetro como um indicador relativo, medindo a expectativa de retorno para cada unidade de capital imobilizada no projeto. Dessa forma, para cada $R \$ 1,00$ investido, será possível gerar $\mathrm{R} \$ 1,29$ a valor presente por meio dos fluxos de caixa futuros, aumentando-se de maneira proporcional à extensão do horizonte de análise, podendo chegar até $222 \%$ de retorno ao produtor. Pacheco et al. (2012) encontraram valor inferior, porém favorável ao produtor, com retorno de $2,5 \%$.

Quanto maior o período de tempo para se recuperar o capital investido, maior o risco do projeto. Nesse cenário em específico, constata-se que o pay back period foi inferior ao prazo máximo de recupera- ção da atividade (10 anos), favorecendo a aceitação do projeto. Entretanto deve ser analisado concomitantemente com outros indicadores, dentre os quais o VPL e TIR já discutidos anteriormente, pois este não é uma medida de rentabilidade, medindo apenas o prazo necessário para a recuperação do capital.

Santos et al. (2011) analisaram a viabilidade econômica da criação de gado leiteiro em um arrendamento rural e observaram rentabilidade média de 33,87\% com tempo de retorno do capital investido em aproximadamente 3 anos. Santos e Lopes (2014) obtiveram rentabilidade negativa para três sistemas de produção de leite em confinamento, entre 2008 e 2009; o mesmo aconteceu com Lopes et al. (2011), trabalhando com terminação de novilhos no ano de 2007, e Pacheco et al. (2014), no ano de 2009. 
Por fim, a melhoria da rentabilidade aplicada à atividade é proporcional aos melhores parâmetros zootécnicos de produção e que, por consequência, suplantem aos investimentos realizados no sistema de produção, sobretudo pelo rápido retorno que a atividade proporciona a quem produz.

\section{CONCLUSÕES}

A pecuária em regime de confinamento, considerando as análises de curto e longo prazo para a atividade, apresenta ser uma atividade rentável e viável, sobretudo por resultar em rápido retorno do capital inicial investido ao empresário rural.

A atividade ainda mostrou um índice de lucratividade próximo de $70 \%$ para o ciclo produtivo, resultando ainda um VPL positivo e uma TIR superior ao custo de capital já para o $4^{\circ}$ ano produtivo, destacando esta como uma atividade com grande potencial de atratividade.

Apesar da alta lucratividade, o sistema de confinamento deve ser analisado com cautela, uma vez que os custos de produção são elevados. Além disso, o produtor deve estar atento às tendências do mercado e ao ciclo da pecuária para conseguir bons preços para reposição dos animais abatidos.

\section{REFERÊNCIAS}

ANDRADE, R. G.; RODRIGUES, C. A. G.; SANCHES, I. D.; TORRESAN, F. E.; QUARTAROLI, C. F. Uso de técnicas de sensoriamento remoto na detecção de processos de degradação de pastagens. Engenharia da Agricultura, Viçosa, MG, v. 21, n. 3, p. 234-243, jun. 2013.

BARBOSA, F. A.; GUIMARÃES, P. H. S.; GRAÇA, D. S.; ANDRADE, V. J.; CEZAR, I. M.; SOUZA, R. C.; LIMA, J. B. M. P. Análise da viabilidade econômica da terminação de bovinos de corte em confinamento: uma comparação de dois sistemas. In: REUNIÃO ANUAL DA SOCIEDADE BRASILEIRA DE ZOOTECNIA, 43., João Pessoa, PB. Anais... João Pessoa, PB: SBZ, 2006. CD-Rom.
BARROS, G. S. C.; SILVA, A. F.; FACHINELLO, A. L.; CASTRO, N. R.; GILIO, L. Relatório PIB Agro-Brasil. Piracicaba, SP: CEPEA, 2014. 17 p.

BRUNI, A. L.; FAMÁ, R. As decisões de investimentos. 3. ed. São Paulo: Atlas, 2007. 197p.

CASTRO,E. R.; TEIXEIRA, E. C;FIGUEIREDO, A. M.; SANTOS, M. L. Teoria dos Custos. In: SANTOS, M. L. dos; LIRIO, V. S.; VIEIRA, W.C. Microeconomia aplicada. Visconde do Rio Branco, MG: Suprema, 2009.

CENTRO DE ESTUDOS AVANÇADOS EM ECONOMIA APLICADA (CEPEA). Relatório PIB Agro-Brasil 2014. Disponível em: <http:// www.cepea.esalq.usp.br/comunicacao/ Cepea_PIB_BR_dez14.pdf $>$. Acesso em: 13 maio 2015.

COMPANHIA NACIONAL DE ABASTECIMENTO (CONAB). Custos de produção agrícola: a metodologia da Conab. Brasília: Conab, 2010. 60 p.

CUNHA, C. A.; MEDEIROS, J. A. V.; WANDER, A. E. Utilização de opções reais na avaliação de confinamento de terminação de bovinos de corte. Custos e @gronegócio On Line, Recife, PE, v. 10, n. 1, p. 212-227, 2014.

DAMASCENO, T. K.; LOPES, M. A.; COSTA, F. P. Análise da rentabilidade da produção de bovinos de corte em sistema de pastejo: um estudo de caso. Acta Tecnológica, São Luís, MA, v. 7, n. 2, p. 18-24, 2012.

DAMODARAN, A. Avaliação de investimentos: ferramentas e técnicas para a determinação do valor de qualquer ativo. Rio de Janeiro: Qualitymark, 1997.630 p.

HUDSON, L. S.; GARCIA, M. A. Sistema agrossilvipastoril: uma opção de rentabilidade e sustentabilidade. 2009. Disponível em: <http://www.ilpf. com.br/artigos/Viabilidade\%20ilpf.pdf>. Acesso em: 11 set. 2015.

INSTITUTO BRASILEIRO DE GEOGRAFIA E ESTATÍSTICA (IBGE). Indicadores IBGE: Estatística da Produção Pecuária. IBGE, 2014. $50 \mathrm{p}$.

LOPES, M. A.; MAGALHÃES, G. P. Análise da rentabilidade da terminação de bovinos de corte em condições de confinamento: um estudo de caso. Arquivo Brasileiro de Medicina 
Veterinária e Zootecnia, Belo Horizonte, v. 57, n. 3, p. 374-379, 2005.

LOPES, M. A.; RIBEIRO, A. D. B.; NOGUEIRA, T. M.; DEMEU, A. A.; BARBOSA, F. A. Análise econômica da terminação de bovinos de corte em confinamentos no estado de Minas Gerais: estudo de caso. Ceres, Viçosa, MG, v. 60, n. 4, p. 465-473, ago. 2013.

LOPES, L. S.; LADEIRA, M. M.; MACHADO NETO, O. R.; SILVEIRA, A. R. M. C.; REIS, R. P.; CAMPOS, F. R. Viabilidade econômica da terminação de novilhos nelore e red norte em confinamento na região de Lavras-MG. Ciência e Agrotecnologia, Lavras, MG, v. 35, n. 4, p. 774-780, 2011.

MARTIN, N. B.; SERRA, R.; OLIVEIRA, M. D. M.; ANGELO, J. A.; OKAWA, H. Sistema Integrado de Custos Agropecuários - CUSTAGRI. Informações Econômicas, São Paulo, v. 28, n. 1, jan. 1998.

MATSUNAGA, M.; BEMELMANS, P. F.; TOLEDO, P.E. N.; DULLEY, R. D.; OKAWA, H.; PEDROSO, I. A. Metodologia de custo utilizada pelo IEA. Agricultura em São Paulo, v. 23, n. 1, p. 123- 39, 1976.

MEDEIROS, J. A. V.; CUNHA, C. A.; WANDER, A. E. Viabilidade econômica de sistema de confinamento de bovinos de corte em Goiás. In: CONGRESSO DA SOBER, 53., 2015, João Pessoa, PB. Anais... João Pessoa, PB: Sober, 2015. p. 1-16.

MOREIRA, S. A.; THOMÉ, K. M.; FERREIRA, P. S.; BOTELHO FILHO, F. P. Análise econômica da terminação de gado de corte em confinamento dentro da dinâmica de uma propriedade agrícola. Custose @ gronegócio On Line, Recife, PE, v. 5, n. 3, p. 132-152, mar. 2010.

NATIONAL RESEARCH COUNCIL (Ed.). Nutrient requeriment of beef cattle. 7. ed. rev. Washington, D.C.: Comitte On Animal Nutrition, 2000. 248 p.

NORONHA, J. F. Projetos agropecuários: administração financeira, orçamentação e avaliação econômica. São Paulo: Fundação Estudos Agrários Luiz de Queiroz, 1981.

PACHECO, P. S.; RESTLE, J.; VAZ, F. N.; PASCOAL, L. L.; ARBOITTE, M. Z.; VAZ, R. Z. Viabilidade econômica da terminação em confinamento de novilhos abatidos com diferentes pesos. Pesquisa Agropecuária Gaúcha, Porto Alegre, RS, v. 18, n. 2, p. 158174, 2012.

PACHECO, P. S.; SILVA, R. M.; PADUA, J. T.; RESTLE, J.; TAVEIRA, R. Z.; VAZ, F. N.; PASCOAL, L. L.; OLEGARIO, J. L.; MENEZES, F. R. Análise econômica da terminação de novilhos em confinamento recebendo diferentes proporções de canade-açúcar e concentrado. Semina Ciências Agrárias, Londrina, PR, v. 35, n. 2, p. 999-1012, 28 abr. 2014.

REIS, R. P. Fundamentos de economia aplicada. Lavras, MG: UFLA/FAEPE, 2007.

SAMANEZ, C.P. Engenharia econômica. São Paulo: Pearson Prentice Hall, 2009. 210 p.

SANTOS, D. F. L.; JURCA, F. L. Análise de investimento em confinamento bovino no centro-oeste brasileiro: um estudo de caso. Custos e @gronegócio On Line, Recife, PE, v. 9, n. 4, p. 129-161, 2013.

SANTOS, G.; LOPES, M. A. Indicadores econômicos de sistemas de produção de leite em confinamento total com alto volume de produção diária. Ciência Animal Brasileira, Goiânia, GO, v. 15, n. 3, p. 239-248, 2014.

SANTOS, R. A.; SOUZA, T. L.; BRAGA FILHO, R. Um estudo sobre a viabilidade econômica da criação de gado leiteiro numa propriedade com arrendamento rural para auxiliar na criação de gado de corte - estudo de caso. Revista Eletrônica Saber Contábil, JiParaná, RO, v. 1, n. 1, p. 56-73, 2011.

SILVEIRA, L. G.; SOARES, M. A.; SILVA, M. A. Rentabilidade do gado de corte na fase de recria: uso da simulação de Monte Carlo para planejamento e controle empresarial. Custos e @gronegócio On Line, Recife, PE, v. 9, n. 4, p. 60-82, 2013.

SIMÕES, André Rozemberg P.; MOURA, Altair Dias de; ROCHA, Denis Teixeira da. Avaliação econômica comparativa de sistemas de produção de gado de corte sob condições de risco no Mato Grosso do Sul. Revista de Economia e Agronegócio, Viçosa, MG, v. 5, n. 1, 2007.

SOUZA, A.; CLEMENTE, A. Decisões financeiras e análise de investimentos. 5. ed. São Paulo: Atlas, 2004. 178 p. 
VALADARES FILHO, S. D.; SILVA, F. F.; ROCHA JUNIOR, V. R.; CAPPELLE, E. R. Tabelas de composição de alimentos e exigências nutricionais para bovinos no Brasil. Viçosa, MG: Simcorte, 2000. 68 p.
YIN, R. K. Estudo de caso: planejamento e métodos. 2. ed. Porto Alegre, RS: Bookman; 2001. 248 p.

\section{Sobre os autores:}

Rayner Sversut Barbieri: Zootecnista, Mestrando do Programa de Pós-Graduação em Agronomia na Universidade Estadual Paulista Júlio de Mesquita Filho/Faculdade de Engenharia de Ilha Solteira (FEIS/UNESP). E-mail: rayner_sb@hotmail.com

Jaqueline Bonfim de Carbalho: Engenheira Agrônoma, Mestranda do Programa de Pós-Graduação em Agronomia na FEIS/UNESP. E-mail: jaquecarvalho.agro@gmail.com

Omar Jorge Sabbag: Professor Doutor, Departamento de Fitotecnia, Tecnologia de Alimentos e Socioeconomia (DFTASE), FEIS/UNESP. Área: Economia e Gestão do Agronegócio. E-mail: sabbag@agr.feis.unesp.br 